\title{
LEER A ASR EN COMPAÑÍA DE JAIME SILES: EXTRAÑA COINCIDENCIA O DES-COINCIDENCIA FAMILIAR. PARA UNA HERMENÉUTICA DE LA HOSPITALIDAD
}

\section{Idoli CASTRO}

Université Lumière Lyon 2 - Passages XX-XXI idoli.castro@univ-lyon2.fr

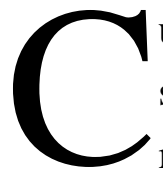

uando Claire Laguian me propuso llevar a cabo una comparación entre estas dos voces y sensibilidades, que la crítica a menudo aproxima, me interrogué desde un principio en la manera de realizar esta lectura conjunta fuera de una postura de asimilación o confrontación, y renovando también mi enfoque silesiano. ¿Cómo enlazar, relegere estas dos voces en co-presencia o en el desvío de la una para (re)acceder a la otra? Ahora bien, apuntar simplemente las diferencias implicaría separar por distinción, abandonando, evacuando al otro, y recalcar las adecuaciones supondría la muerte del deseo hermenéutico; deseaba más bien captar, en estas obras, las zonas de desfase donde se abre un «entre», ese punto intermedio (que in-dispone obviamente al lector, lo saca de su zona de comodidad) en el que se mantiene la mirada del otro, en el que la mirada (y la voz) del otro comparte o molesta, ese otro que siempre nos cuestiona, nos hace desviar, descoincidir con uno mismo. Siguiendo unas reflexiones propuestas por el filósofo francés François Jullien, en una conferencia en la universidad Lumière Lyon 2, el 11 de enero del 2017, titulada «Décoïncidence et invention», me pareció que el proceso dialéctico de coincidencia/des-coincidencia traducía el encuentro de estas dos voces, en aparente adecuación, pero que en su 'caer juntas' (cumincidere proviniendo del verbo cadere) operan una leve desviación, a la manera del clinamen de Lucrecio $^{1}$, permitiendo así que algo advenga, ocurra, 'incida', lo contrario de una adecuación perfecta que no dejaría ya nada que desear. Es precisamente en estas sucesiones de coincidencias extrañas y des-coincidencias familiares en las que se aloja la alteridad, encaminando nuestra interpretación hacia una forma dialógica, alteridad que, tras el estudio de una estética de lo precario en las dos obras, - como huella de una carencia ontológica y existencial, y vinculada con una plegaria ya imposible-, nos llevará a la toma en consideración de una po-ética de las hospitalidades silesiana y robayniana.

\footnotetext{
${ }^{1}$ Ese momento de desvío, de des-coincidencia de los átomos en su caída favorece una coincidencia activa, ya no en el sentido de una adecuación sino de un 'caer en'.
} 


\title{
Idoli Castro
}

\section{Entrada en materia}

\author{
Ahora entramos en la penetración, \\ en el reverso incisivo \\ de cuanto infinitamente se divide. \\ [...] \\ en el revés de la pupila, \\ en la extremidad terminal de la materia \\ o en su solo comienzo. (Valente, 2005: 159)
}

Estos primeros versos, casi premonitorios, del poema «Territorio», sacado del poemario Interior con figuras que José Ángel Valente publicó en 1976, nos parecen traducir las primeras sensaciones lectoras que nos otorgan las dos trayectorias poéticas conjuntas de Siles y Sánchez Robayna. En sus albores, percibimos su arraigo en una poética de lo sensible, cuyas funciones afectivas y cognitivas implican a la vez un 'ser afectado' y una 'toma de conciencia': «à la fois je deviens dans la sensation et quelque chose arrive par la sensation, l'un par l'autre, l'un dans l'autre» (Deleuze, 1994: 27). Esta poética de lo sensible concuerda obviamente con una poética de lo elemental - el elemento concebido como principio constituyente del Ser y sustancia misma del universo:

Élément au sens où on l'employait pour parler de l'eau, de l'air, de la terre et du feu, c'est-à-dire au sens d'une chose générale, à mi-chemin de l'individu spatio-temporel et de l'idée, sorte de principe incarné qui importe mon style d'être partout où il s'en trouve une parcelle. La chair est dans ce sens un «élément» de l'Être. (Merleau-Ponty, 1964: 184)

Esta poética de lo elemental es la que nos obliga a releer dichas obras y su relación con la naturaleza a través de una conciencia crítica renovada, a la luz de una ecocrítica, puesto que en ellas no constituye la naturaleza un mero tema romántico y antropomórfico, cuya representación estaría al servicio de los cuerpos, deseos y estados de ánimo humanos, sino que participa de una relación más consciente del hombre con su medio ambiente, reconociendo una «interdependencia entre lo humano y lo no-humano», cierta humildad, y «la exigencia de cierto escepticismo en cuanto a la posibilidad de producir una verdad a partir de esos vínculos» (Moudileno, 2016: 46) ${ }^{2}$. Ese grado de conciencia y de interdependencia fundada en una 'intercorporeidad' ${ }^{\text {'3 }}$ evidencia las consecuencias de una reversibilidad de lo visible, quiasmo original del sentir y del mundo propio de una ecopoesía ya sea «presentida» por Andrés Sánchez Robayna en su poema-poemario Día de aire (2015: 15) y asumida en el título de su poemario Clima («En el mar / visible, divisible», donde la voz poética se define como «actor», «difusor» (2015: 21)), ya sea intuida en las primeras líneas del poema en prosa liminar del poemario silesiano Canon, donde se expresa ese fluir carnal «sin espacio» («Mis labios llegan a la playa más alta, a la arena más honda, a besar esos átomos, sin espacio, del aire» (1992: 45)).

\footnotetext{
${ }^{2}$ Me apoyo aquí en la síntesis (que traduzco) propuesta por Lydie Moudileno en su artículo sobre Monchoachi titulado «Écopoésie de la Caraïbe (Monchoachi, le lieu)».

${ }^{3}$ Término cuya resonancia fenomenológica permite com-prender el quiasmo entre el cuerpo humano, el cuerpo del mundo y el cuerpo del lenguaje.
} 
Habiendo dedicado un capítulo entero a este quiasmo fundacional en mi estudio dedicado a Jaime Siles, Une poésie de la pensée et une pensée poétique (Castro, 2009), y ya que, en el presente número, Candelas Gala le dedica a A. Sánchez Robayna un estudio ecocrítico fundado asimismo en las teorías de Merleau-Ponty, no pretendo volver sobre este aspecto que corresponde sin duda al mayor grado de coincidencia entre ambos poetas ${ }^{4}$. Coincidencias que sin embargo no dejaron de extraviarme con trampas 'sensitivas' en mis primeras lecturas conjuntas, cuando me parecía predominar tal o tal elemento, como las aguas resecas y la poética de la piedra robayniana en apariencia opuestas a la «música de agua» silesiana, oposición pronto contrariada por los dípticos de la piedra silesianos o las aguas invasoras robaynianas. Así pues, lo que surgía como diferencias no eran sino momentos de dis-yunción (el famoso out of joins shakespeariano en que François Jullien basa su teoría ${ }^{5}$ ), de di-ferencia temporal. Parémonos un instante en los momentos iniciales de la 'entrada en materia' de ambas obras, para vislumbrar tal vez cómo esta ecopoética no hace más que revelar, en el sentido casi fotográfico, el negativo de una poesía precaria, propia de unas sensibilidades contemporáneas.

Los títulos de los dos primeros poemarios, Día de aire (Sánchez Robayna, 1970) y Génesis de la luz (Siles, 1969) atestiguan un comenzar mutuo bajo el signo de lo diurno, en relación con una búsqueda linguística a lo largo de un caminar «mudo» para Sánchez Robayna, a fin de «[excavar] en la orilla la palabra / que dice el mar soplado. La palabra / que late desde el fondo de la roca» (2015: 16) y «la palabra que sea alumbramiento» (2015: 17), o «alaridos de júbilos» para el joven Siles (1992: 15) cuya voz reconocerá en el poema «Biografía» (del poemario posterior) que su «ayer son algas de pasión» (1992: 31). El esquema de lo diurno conlleva, desde un principio, la cara nocturna del imaginario que clausura por ejemplo el primer poema de Sánchez Robayna: «La noche toma el oleaje» (2015: 17). Ese esquema de lo diurno y nocturno apunta, en las primicias de ambas obras, la reversibilidad de lo visible e invisible. Sin embargo, notemos una impulsión tipográficamente violenta en la idea de génesis silesiana, génesis casi enloquecida de esas «lenguas [que] airean sus raíces y los ojos / [que] escriben soliloquios en las nubes» (1992: 13). La voluntad de ruptura y la forma discontinua barroca (que persiste en parte en un poemario como Canon escrito entre 1969 y 1973) parecen contrastar con la voz de Sánchez Robayna del primero y extenso poema-poemario en la estabilidad fluida de sus cuartetos. En efecto, la voz «de rabia e ira» (1992: 19), el «grito» silesianos (1992: 13) impersonales, mordaces (con el motivo carnívoro, rabioso de los dientes) emana de un cuerpo fragmentado (Castro, 2009: $90 \mathrm{sq}$.), aferrado a pronombres posesivos en primera persona, y escasamente en segunda persona, en una empresa voluntaria de «des-significación» ${ }^{6}$ que

\footnotetext{
${ }^{4}$ Aunque el conjunto de mi ensayo se fundamenta en las teorías de Maurice Merleau-Ponty, en el segundo capítulo, titulado «Des signes du corps aux corps du signe», es donde insisto en las modalidades de un principio encarnado, pp. 85-141.

${ }^{5}$ Explicado en la conferencia anteriormente evocada.

${ }^{6}$ Recordemos que Siles explicita esta noción en la Nota del autor de su Poesía 1969-1980, publicada en Visor en 1982: «Toda obra es, necesariamente, supresión. Y, también, negación. Y, sobre todo, historia. El conjunto de signos que se reúne aquí no constituye un texto: configura una des-significación. No es lo que el lenguaje da, sino lo que el silencio niega» (1982: 7).
} 
anuncia el último verso del poema final «Memorial»: «soy mi asesino mi dueño mi tumba y tu mirada» (Siles, 1992: 25) y que confirmará el poema «Siesta» del poemario siguiente : «Todo un mar se desgrana: sin olas, sin sentido» (1992: 35). No obstante, la aparente calma inicial de Día de aire, reescrito en 1985 como «la consciente expresión de esa otredad» (Sánchez Robayna, 2015: 275), sus verbos conjugados en segunda persona del singular — esa persona del verbo intermedia, enlazadora entre un yo y un él- no hace más que diferir la resonancia de un grito humano que se eleva en el poema «Pájaros» de Clima (motivo crucial en Siles aún, por su ligereza y su habitar el cielo): este animal celeste, tal como las «nubes a ras del agua», desciende «en las rocas», y desde aquí abajo «llamea el lenguaje lleno de lunas / sordo solo sube / ahora un grito / humano» (Sánchez Robayna, 1978: 60). Dicho grito humano robayniano se plasmará en un proceso de desgrane tipográfico en el último poema de Clima: «El sentido del poema ha de ser destruido» (Sánchez Robayna, 1978: 99101) o en «Fragmento» del poemario Tinta (2015: 43). Los desgranes robayniano o silesiano, bajo diversas modalidades, corresponden, a mi parecer, al negativo de la reversibilidad carnal de lo visible, e introducen, junto a la poética de lo sensible, una poética de la carencia partícipe de una poesía precaria. Si la a-percepción ${ }^{7}$ de la nada, a menudo sonora en Siles, evidencia en ambas obras esta carencia, también la recalca la conciencia temprana de la otredad expresada por ejemplo en la reescritura de Día de aire. En este poemario, la otredad implica extrañeza, la de una segunda persona falsamente dialógica o que intenta introducir la estructura del diálogo en la voz misma, como expresión de un pronombre en realidad anónimo que generaliza una experiencia personal. Ese tú, ilusorio compañero locutivo, desvela la soledad «muda» de un yo poético que se habla a sí mismo tal vez para intentar salvar el «acto del habla», fundamental, aunque efímero, en la preservación del idioma $^{8}$. Esa soledad, presente pero como ocultada por la fuerza del grito en el primer poemario silesiano, surge más nítidamente en los escuetos poemas de una Biografía sola (1970) y se escenifica en un «ir de ti hasta ti: / para mí soledad» (Siles, 1992: 33).

\section{Una poesía precaria}

Sola llama visible que convoca

a lo invisible, lengua de silencio

pobre, vencido, solitario; luz

de oscuridad, de desconocimiento.

[...] En el cuarto en silencio, solamente

una llama es pensada, y en la mesa

ella es la única verdad, la entera

desposesión. Se extingue aquí una vela

encendida en su nada, en la pobreza,

en el origen, llama llamadora9 ${ }^{9}$ (Sánchez Robayna, 2015: 93)

\footnotetext{
${ }^{7}$ Término que traduce el proceso de concienciación llevado a cabo en el acto de percepción.

${ }^{8}$ Véase el poemario de Jaime Siles titulado Actos de habla (2009) y la « Poética dedicatoria » que inicia Colección de tapices (2008).

${ }^{9}$ Subrayo las palabras en negrita.
} 
Estas cuantas estrofas del poema «Para la llama de una vela» parecen explicitar el vínculo entre reversibilidad de lo visible y poesía precaria, centrándose en el destino efímero de una llama encendida en una serie de tercetos, compuestos de endecasílabos cuyo esbozo de rimas fracasado traduce la fragilidad de dicha llama. El sinónimo contemporáneo de precario se halla aquí derivado en los vocables «pobre, pobreza» pero aún más en la derivación, recurrente en Robayna, del adjetivo y adverbio «solo, solamente» que arraigan una estética de la carencia, recordándonos así ciertos versos del peruano César Vallejo. El concepto de 'poesía precaria' fue elaborado por el crítico francés Jérôme Thélot en los términos siguientes:

La prière n'étant pas seulement un thème mais un fait, et ce fait n'étant pas parmi d'autres, mais tel que s'y décide le sens des œuvres, celles-ci pourraient être dites religieuses ou mystiques si les dieux les précédaient, les autorisaient et les justifiaient comme jadis. Mais désormais moderne, c'est-à dire sans les dieux, la poésie est précaire, le sens étymologique de ce dernier mot étant ici ranimé dans son acception courante. Précaire, du latin precari, veut dire : obtenu par la prière, donc permis par une puissance supérieure, donc susceptible d'être retiré, par conséquent fragile et pauvre. Précaire est la poésie moderne, en ceci qu'elle tient de la prière impriable, en ceci, donc, qu'elle est l'essentielle pauvreté d'être défaite de l'oraison. (Thélot, 1997: 9)

La vivencia de la ausencia de Dios se halla transcrita en ambas obras que hacen 'resonar' la historia mística de la humanidad. En efecto, la expresión de una precariedad poética radica más bien en anotaciones auditivas, como por ejemplo en «Silencio», poema donde se expresa un «Todo: / un espacio sin voz / hacia lo hondo oculto» (Siles, 1992: 32), o sea camino inverso al cielo, a aquella «Eternidad del aire», otro poema silesiano donde «Dios estrangula un pájaro de cobre» y cuyo último tríptico instala la eternidad en lo profundo, lo hondo oscuro y no en las alturas aéreas («Eternidad. Honda. Sin luz. / ¡Pasión de todo instante!») (1992: 33-34). Tras la caída de Dios, representado en la playa del poema «Siesta», a través del motivo del «caballo de oro» (Siles, 1992: 35), sólo permanece una «palpitación [...] eternidad huída» (1992: 36). Asimismo aparece en la obra robayniana el habla del silencio o la figura de un dios en el suelo, o más precisamente en las aguas, «herido» a semejanza del cielo (2015: 117-118); estas representaciones se hacen eco de unas manos bajadas «de antigua adoración», «antigua convocación» (2015: 118), o eco de la «voz humana herida de sed [...] / bajo la soledad del sol sin la presencia, / cegado y solo un mundo sin respuesta, sin voz» que el poema «La espera, al sol» lanza a través del grito del yo poético (Sánchez Robayna, 2015: 85). La herida, la caída de lo divino impacta la resonancia de la voz poética que retumba entre las rocas robaynianas o a punto de cesar, en los Dípticos de la piedra (Siles, 1992: 17) ${ }^{10}$. Influye también en el modo de 'habitar' en la tierra y bajo el cielo, ese habitar del poeta que, según nos explica Heidegger, es el que toma la medida: «entendue en son sens rigoureux, prise par laquelle seulement l'homme reçoit la mesure convenant à toute l'étendue de son être» (Heidegger, 2001: 235); y considera la extensión de su ser como: «l'entre-deux qui conduit l'un vers l'autre le ciel et la terre [...] Car, l'homme habite en mesurant d'un bout à l'autre le "sur cette terre" et le "sous le ciel"» (Heidegger, 2001: 234-238). La toma de medida no puede asimilarse a una voluntad de dominar o de poseer, a semejanza de nuestra

\footnotetext{
10 Trabajando sobre la voz en construcción silesiana, tuve la oportunidad de dedicar un capítulo a Eco, relacionando el mito con el fenómeno: «La cité de la poésie : écho(s) d’une voix fragmentée» (Castro, 2009: 19-84).
} 
sociedad bajo control, cuadriculada, captada por la voz silesiana en Semáforos, semáforos (Castro, 2003: 449). Cumple un deseo de ir hacia, de salir del ensimismamiento, lo que no permiten forzosamente las edificaciones humanas — «aquella construcción [que] se alzaba entre la tierra y el cielo» y que la voz robayniana denuncia «como imposible lugar de mediación entre la humana lengua y la lengua del dios» (2015: 119)_, pero lo que sí admite el compás de un verso (recordemos la importancia de la medida métrica para Jaime Siles, obsesión métrica que va in crescendo en sus últimos poemarios), o su verticalidad. Demos el ejemplo de los poemas verticales titulados «La barca» (Sánchez Robayna, 2015: 60, 68) cuyo simbolismo implica un rito de paso: ¿paso entre la tierra y el cielo?, paso que se horizontaliza en los dípticos del tercer poema con título similar (Sánchez Robayna, 2015: 91). La preocupación por la medida, que cuestiona, más allá del habitar poético, un habitar humano tocado por la precariedad, por ese «ser menos que», se manifiesta en esta estrofa del poema «Sobre una confidencia del mar griego» (cuyo título ya despierta toda una historia de la humanidad):

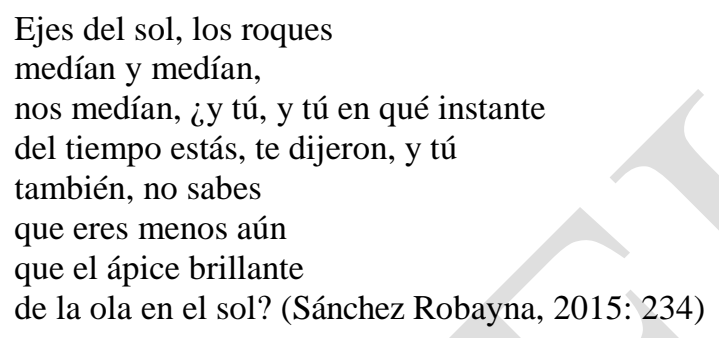

También me parece llamativo en Sánchez Robayna el poema «Estancia» del poemario Clima. Recordemos la etimología de la palabra «clima», cuyo significado latín ya suponía una inclinación del casquete celeste, inclinación del cielo sobre el «Oh terrestre / momento / de ser en luz no humana», del que la voz apunta otra vez la mudez, la «calcinada respuesta» y al que incita en una plegaria invocadora (que la interjección «oh» y el apóstrofe «Alto» alzan) e imperativa («mírate») a «[mirarse] en ese responsaje» (Sánchez Robayna, 1978: 79). Unos versos de dicho poema entrañan ese deseo propio de la toma de medida, anteriormente evocado, y que apromixa la voz robayniana a la «función de oración» del poeta francés Yves Bonnefoy, tal como la estudia Jérôme Thélot, citando unas palabras de Bonnefoy:

"Mais ce que je sais pour ma part, écrit Bonnefoy, c'est que la poésie revient irrésistiblement respirer - par un besoin de survie qui la révèle en son être propre — au plus près de ce point de ténèbre et de devenir, ayant en elle l'espoir, l'espoir comme natif, qu'il va se passer quelque chose..." Cette intuition, ou cette exigence, qu'il va se passer quelque chose là où il ne peut rien se passer, là où les évidences de la raison et les nécessités de l'être certifient qu'il ne se passera rien, notons qu'elle est identifiée à la "poésie" comme tel. Réclamer l'impossible, se consacrer à vouloir que se produise ce qu'on sait qui ne se produira pas - changer la vie, disait Rimbaud —, ce serait, ce désir du miracle, l'essence de la "poésie" : de sorte qu'il n'est pas étonnant que celle-ci, au moins quelque fois, se fasse prière. (Thélot, 1997: 105)

Este algo por ocurrir se oculta pues tras los versos siguientes: «El sol sangriento en lo no dicho / reposa / sobre lo por decir ${ }^{11} \gg$ (Sánchez Robayna, 1978: 78) o tras las evocaciones en ciertos poemas de un dios durmiendo en la «piedra henchida» (Sánchez Robayna, 2015: 17). Una intuición

\footnotetext{
${ }^{11}$ Subrayo este sintagma clave.
} 
análoga ya se encontraba en el «Retablo de la muerte de nuestro señor Jesucristo» con la evocación de una «ciudad venidera»y «el sueño de una claridad» (Siles, 1992: 113; 115). Sin embargo, aunque en ambos poetas esta intuición no coincida necesariamente con una creencia religiosa, descartando la revelación de un dios («Creer fue sólo / el primer espejismo», «¿A qué Dios has venido a buscar en la isla / [...] / nada / te será revelado» (Sánchez Robayna, 2015: 156; 263)), sí que en ella se reivindica un sentido místico del relegere posible por el lenguaje poético. En efecto, para Jaime Siles «Dios es un lenguaje [...] un signo puro que habla por señales / y existe sólo donde termina el yo» (1999: 29): forma flexible, la palabra «Dios» (y los artículos indefinidos que la determinan a menudo) llega a ser, no sin cierta ambigüedad, un vocablo por colmar, «dueño de lo imposible» (1999: 27), a la vez que un movimiento similar al de las hojas (1999: 28) y/o del hombre, en la vivencia de una ecopoética ${ }^{12}$. No falta tampoco en Robayna la asimilación de esta presencia (portadora de «esperanza», palabra clave que nos recuerda a Bonnefoy) al lenguaje, percibido como siendo «al mismo tiempo» la «destrucción» y la «construcción de todo» (2015: 131), incluyendo a menudo la idea de salvación (2015: 188; 264) que alcanza en Siles la de resurrección (1999: 53), pero lenguaje que nos incita paradójicamente a volver al rumor de los árboles (Sánchez Robayna, 2015: 131; 134) en una auténtica ecopo-ética ${ }^{13}$. La poesía robayniana nos da a veces la impresión de una anterioridad de la naturaleza sobre el lenguaje, o sea la naturaleza como punto de partida y regreso, «fin y origen» de una voz poética en sintonía con «la lengua de la tierra» $(2015: 133,134)$, una naturaleza concebida como una «llamada del lenguaje», «un más allá de él» (132): «que esa lengua sea la del cuerpo del mundo» (134). El subjuntivo de este verso abre el espacio de la oración, que no se restringe a la oración tradicional y tópica del hombre hacia una posible divinidad, sino que retumba a modo de definición intrínseca como aquella «llamada» de la poesía al mundo. Ahora bien, cuando esta llamada orante se pone a preguntar, asistimos a una como conversión de la poesíaoración en la poesía-pregunta de nuestra contemporaneidad (véase por ejemplo la multiplicación de la forma interrogativa precisamente en el poemario silesiano Himnos tardíos donde el uso de la palabra «dios» es frecuente). ¿No participa esta interrogación de una forma de hospitalidad poética más auténtica y libre, en parte (aunque no plenamente) librada de la precariedad o sea de la dependencia del otro percibido como dueño, de la autoridad y autorización de una potencia superior (Thélot, 1997: 9)? Una pregunta que permite cierta duración, lo que no autoriza el estado provisional de lo precario ${ }^{14}$ :

\footnotetext{
Y la pregunta

dura a través de toda duración,

como si sólo la pregunta fuera

la casa que habitamos, nuestro aire

en la respiración entre lo uno. (Sánchez Robayna, 2015: 157),
}

\footnotetext{
${ }^{12}$ Véase el apartado «El hombre es el sueño de una claridad» (Castro, 2009: 187-193).

${ }^{13}$ Explicaré a continuación esta posible des-coincidencia entre ambos poetas.

14 Recordemos la acepción contemporánea del vocablo «precario», según la RAE, a saber «de poca estabilidad o duración, algo provisional, que se tiene por tolerancia del dueño, o sea cuestionable».
} 
o una pregunta que se difracta a través de una reduplicación del pronombre interrogativo «quién» y de un movimiento amplio de alternancia métrica que se expande en el espacio temporal del pasado, presente y futuro:

\author{
[...] Y, luego, pregunté \\ quién era aquel que hacía \\ esa misma pregunta, \\ y quién hablaba en mí, quién preguntaba \\ por quién, quién eres, quién responde en ti \\ a la pregunta de quién eres, quién \\ habitaba y habita \\ y quizá va a habitar \\ en ti, quién con tus manos y tus ojos \\ podrá decir quién es. (Sánchez Robayna, 2015: 203)
}

\title{
A modo de epílogo: una poética de la hospitalidad
}

Por cierto, este preguntar desemboca en un yo «multiplicado», disperso en «fragmentos», y la ausencia de respuesta le hace conocer «tan sólo su vacío» (Sánchez Robayna, 2015: 203-204), vacuidad que tal vez podamos interpretar en ciertos poemas como una vacancia, lo que implica etimológicamente un sitio libre para acoger la alteridad. Señalemos que esta percepción de la vacuidad coincide de cierta manera con una afirmación de un «no saber», incluso «del sentido de la ignorancia» (Sánchez Robayna, 2015: 116), y con la aceptación de los «ángulos muertos» en un «ignorar lo que [uno sabe]» (Siles, 1999: 79), en un perderse incluso un borrarse (los Desnudos y acuarelas de Siles pintan esta retracción ya presente en los Himnos tardíos) a fin de poner a disposición «espacios de intercambio» donde a menudo «se "radicalizan" los modos de escritura en un trabajo de extranjerización de la lengua que amplifica aún la intencionalidad crítica y transitiva» (Lloze, 2013: 15: 123) $)^{15}$ :

Et ce travail le plus souvent témoigne d'un salutaire refus de tout esthétisme devenu à la fois désuet et inadmissible en ces «temps de détresse», mais surtout un désespoir malgré tout plein d'espérance ${ }^{16}$, qui trouve dans «l'insécurité, l'inquiétude: la question» comme dans «l'incertitude inventive de son dit» ${ }^{17}$ l'envie et les moyens peut-être de redonner sens à un certain humanisme, la force du moins d'imaginer que «toute poésie travaille à une ouverture (de quelque espèce qu'elle soit, et pas seulement politique, et aussi bien sans le vouloir) $\gg^{18}$, c'est à dire que l'anime manifestement une double perspective faite de prégnance subversive et d'exigence vocative. (Lloze, 2013: 15)

La cuestión de la retracción me parece primordial en Sánchez Robayna en coherencia con una ecopo-ética, mientras que en Siles coincide mejor con una eco-poética, en un casi juego de escondite en busca o en desenmascaramiento del yo. Diría que la eco-poética mantiene la idea de una morada

\footnotetext{
${ }^{15}$ Propongo aquí una traducción de la versión francesa.

${ }^{16}$ La autora nos explica que parafrasea aquí a Yves Bonnefoy.

${ }^{17}$ Estas citas están sacadas de Edmond Jabès, Le Livre du partage, París, Gallimard, 1991, p. 68, y de Le Livre du dialogue, París, Gallimard, 1990, p. 45.

${ }^{18}$ Esta cita está sacada de Philippe Jaccottet, Écrits pour papier journal. Chroniques, 1951-1970, París, Gallimard, 1994, p. 276.
} 
de discurso (en el sentido etimológico de la palabra «ecológico», compuesta del griego oikos y logos). El oikos, la morada de la voz que funciona a modo de disfraz de lengua le permite también romper la ilusión de un yo, a través de un «desmí», un «desyo» escrito «en el revés del mirador del desdesojo» (Siles, 1999: 25), a través del juego del «yoyear»y de sus ecos del ego (Siles, 2008: 15) no desprovisto de cierto humor en este poema de Actos de habla: escribir para desvelar las diversas máscaras del yo y acoger o interrogar aun las del propio lector, otra figura del otro muy presente en su obra. En el dialogismo silesiano impera el baile de las personas del verbo, cuestionadas precisamente en el escenario del mundo que habitan, de ahí pues la interpretación ecopoética posible ya que «existe sin nosotros todo lo que nos mira» (1999: 15). Con cierta des-coincidencia, en el dialogismo robayniano se despliega una perspectiva ética (ecopo-ética) reforzada, que si bien presenciamos una actuación en la «Escena» del mundo de un yo que se pretende «actor», afirmación matizada por la yuxtaposición del vocablo «difusor» (2015: 21), la voz poética consigue a veces aceptar un 'dejar ir', impregnado de filosofía extremo-oriental. Digamos que trasciende una escritura metapoética en un proceso de re-localización, en una poética del lugar que nos recuerda la obra de Olvido García Valdés (el motivo de la casa siendo central): el ethos poético, desde su 'estancia' verbal adhiere al cuerpo de la tierra, que tal vez le infunda mayor «Unidad» ${ }^{19}$ (Sánchez Robayna, 2015: 44) que la fragmentación a la que lo conducen los meandros metapoéticos en «Fragmento» (43) del poemario de título significativo Tinta, o «la ley ciega / que dice [su] destino de palabras» (273). En «las imágenes de la meditación» surgen los vocablos «armonía, paz, quietud, concordia, unidad» (217) que nos confirman que esta «estancia bajo el sol» supone «un ensayo de quietud» (45) que el motivo recurrente y metafórico del «vaso de agua» corrobora. «El sol confluye aquí y allá, y presencia y ausencia son formas giratorias» (45), en la alternancia del yin y del yang en el transcurso natural de las cosas o sea en el Dao: no deja duda la influencia en Robayna de la filosofía extremooriental a lo largo de su obra ${ }^{20}$.

En coherencia con esa alternancia del yin y del yang, no significan esta «Unidad» (Sánchez Robayna, 2015: 44), este adherir al cuerpo del mundo, la ausencia de notas de disonancia como lo muestra la inserción de «bolsas de plástico brillante y negro», relacionadas con «los pájaros negros» (44) de mal agüero. Sin embargo, incluso lo disonante encuentra su lugar entre esos «arbustos displicentes» pero «obedientes», siendo las bolsas «movidas por el viento» (44). El poema en prosa, y sus yuxtaposiciones sintácticas, proceden a esta asimilación de lo otro, de lo intruso aun contaminador, en una perfecta ad-aptación de la naturaleza que ata, liga (recordemos el latín apere

\footnotetext{
${ }^{19}$ La forma de poema en prosa de «Unidad » traduce ese adherir al cuerpo del mundo.

${ }^{20}$ Sería necesario profundizarla, para ver de dónde procede ya que parece surgir nítidamente en los albores de su obra. Para Siles, será más bien el viaje a China el que lo impactará, aunque con la impresión de un recordar o un revivir como lo apuntó en una «Nota a "Cinco poemas chinos..."» de Pasos en la nieve (2004: 175). Si tuve la oportunidad de dedicar un artículo a la emergencia de la poesía china en los paisajes silesianos (2008: 683-699) y de apuntar esta forma de 'hospitalidad' del otro en el impostar extremo-oriental de la voz silesiana, me parece hoy que este impacto no contribuyó necesariamente a un giro poético, sino que permitió escenificar una vez más otra forma de disfraz de la persona verbal. Al contrario, me da la sensación de que, en Sánchez Robayna, desde su 'casa' insular (espacio que ya participa de un ethos poético distinto al de un territorio geográfico — que no político— peninsular o continental europeo), la voz po-ética de entrada es otra.
} 
como raíz del verbo adaptare) los elementos que la componen. La mirada horizontal (plasmada por la forma del poema en prosa) hacia el mundo exterior nos lleva a la conclusión que «desde la ventana, todo respira y se responde» (44), contrariamente a una mirada narcísica hacia dentro o hacia un más allá inasible e invisible (45). En la primera sección del poema «Tinta», tenemos la impresión de que quizás la lengua poética intente seguir el ejemplo de esta naturaleza cuando procede por acumulación de palabras hasta no construir el sentido (que no significa siempre una deconstrucción), como en un intento de dejar que «ese texto» a semejanza del texto del mundo se «engendre»solo, sin principio en mayúscula, sin puntuación, sin la intervención de una «mente» ordenadora, en el 'desprenderse' propio de una ética extremo-oriental:

\footnotetext{
oscuro reposa sobre sí mismo reaparece cada noche ese texto se engendra cada noche y en la mente baldía ulula fijo falda negra y desierta y exacta sobre sí misma inscrita escrita

abajo el escollo la roca más desierta viento salado lacas tilos el oleaje roto que se enarca en plena oscuridad y la rama que cede al soplo súcubo (47)
}

Estos versículos parecen escribirse desde un fuera de sí, en una ética del care que se centra cada vez más en la naturaleza, en la tierra a la que la voz poética se dirige en el poema «En el centro de un círculo de islas»: «Tierra del nacimiento y la extinción / ¿adónde avanzas tú?» (243).

En la aproximación silesiana de la tinta y de la noche del poema «Lectura de la noche», la segunda persona corresponde sobre todo a un diálogo metapoético que desemboca en «el alfabeto nocturno de la nada» (Siles, 1994: 168), porque el cuerpo del signo no hace más que hacerse eco de sí mismo como lo atestigua el juego aliterado de «Tinctus colore noctis» (165) escrito en primera persona. La primacía del lenguaje se afirmará también en la última estrofa del poema «El mar contra la nada»: «Lenguaje. Sí: lenguaje. / Materia, mundo, magma» (199). El lenguaje sigue siendo la materia prima y obsesiva silesiana, como su disfraz 'natural' e intrínseco ${ }^{21}$. Podemos pensar que para este poeta ante todo «clásico contemporáneo» (Morcillo, 2002), la edad clásica va a marcar una ruptura con la naturaleza (según nos explica François Jullien en la conferencia ya evocada), y lo que se sustituye a dicha naturaleza es «el juego, el hiato, como antítesis de la naturaleza, en la denuncia de su tranquilización ${ }^{22} »$. François Jullien nos da el ejemplo de Mallarmé, como poeta de la descoincidencia, de la primacía del juego, del azar, de un comenzar con nada, excepto un lanzar de dados. Ahora bien, cuando leemos Colección de tapices (2008), tenemos la sensación de un refuerzo del juego lingüístico, de las aliteraciones y asonancias, de la rima, que no acarrea estancamiento de la forma sino la apertura de un dialogismo del humor con el lector y con sus propios textos, con este regreso por ejemplo del «tinta, teclado, tacto, texto» (63). Se dirige en imperativo a Dios ( a modo de desafío?), para que, de cierta manera, lance correctamente los dados del azar a lo largo del tiempo: «Remueve, Dios, remueve / La nada de mi sueño / Y haz que el tiempo traduzca / Tu sonido perfecto» (63). El último poema «El colibrí atardece» corrobora este golpe de la suerte, como entidad

\footnotetext{
${ }^{21}$ Para profundizar este aspecto, véase la monografîa escrita por Henry Gil, La poésie de Jaime Siles. Langage, ontologie et esthétique.

${ }^{22}$ Cito aquí a François Jullien: «dénoncer la rassurance de la nature».
} 
indefinida (un dios): «Mientras un dios se bebe nuestro vaso / Y lo arroja, vacío, por ahí. / [...] / La nada va guiando nuestros pasos» $(78)^{23}$.

Tras un intento de cruzar voces fraternales para que entren en resonancia a fin de testimoniar de una sensibilidad contemporánea humanista, quisiera aquí hospedar las palabras del poeta Antoine Emaz, desde una lengua otra, para seguir abriendo este espacio del diálogo propio de los poetas:

[la poésie est]: un espace vide, ouvert à la résonance de toute voix humaine depuis le cri jusqu'à la rhétorique la plus savante. Et la question du nombre d'auditeurs ne se pose pas: voix qui crie dans le désert vaut voix haut parlée face à une foule. Mais il s'agit toujours de la résonance la plus intime de l'humain à travers un dispositif de langue qui permet le partage. Pour cette raison, la poésie est nécessaire et sa fin impossible, sauf disparition de l'espèce. Pour cette raison également, la poésie est urgente car le plus précieux de l'humain, «l'espace du dedans» semble rétrécir aussi vite que l'espace du dehors, le milieu naturel $^{24}$. (Lloze, 2013: 8)

\section{Bibliografía}

CASTRO, I. (2003): «Semáforos, semáforos : un recueil habité», en J. SOUBEYROUX, ed., Le Moi et l'espace. Saint-Étienne, PUSE.

(2004): «L'émergence de la poésie chinoise dans les paysages silésiens : l'exemple de "Pintor chino y paisaje"», en Ph. MEUnIER, E. SAMPER, eds., Mélanges en hommage à Jacques Soubeyroux. Saint-Étienne, Éditions du CELEC.

- (2009): Jaime Siles, Une poésie de la pensée et une pensée poétique. Saint-Étienne, PUSE.

Deleuze, G. (1994): Francis Bacon. Logique de la sensation. París, éd. De la Différence.

HeIDEgGer, M. (2001): Essais et conférences, trad. A. PreAu. París, Gallimard.

GIL, H. (2014): La poésie de Jaime Siles. Langage, ontologie et esthétique. Lyon, ENS Editions.

LlOze, E. (2013): Poésie et question. De la poésie comme pensée critique de l'hospitalité. Bruselas,

La Lettre volée.

MERLEAU-Ponty, M. (1964): Le Visible et l'Invisible. París, Gallimard.

Moudileno, L. (2016): «Écopoésie de la Caraïbe (Monchoachi, le lieu)», en B. Bonhomme, I.

CASTRO, E. Lloze, eds., Dire le réel aujourd 'hui en poésie. París, Hermann, pp. 43-56.

Morcillo, F. (2002): Jaime Siles: un poète espagnol «classique contemporain». París,

L'Harmattan.

SÁnchez Robayna, A. (1978): Clima (1972-1976). Barcelona, Edicions del Mall. (2015): Al cúmulo de octubre (Antología poética: 1970-2015). Madrid, Visor.

Siles, J. (1982): Poesía 1969-1980. Madrid, Visor.

- (1992): Poesía 1969-1990. Madrid, Visor. (1999): Himnos tardios. Madrid, Visor. (2004): Pasos en la nieve. Barcelona, Tusquets editores.

\footnotetext{
${ }^{23}$ Recordemos que también Sánchez Robayna evoca esa «ley ciega / que dice tu destino de palabras» (273).

${ }^{24}$ Recojo aquí un fragmento del prefacio escrito por el poeta Antoine Emaz en el ensayo de Évelyne Lloze.
} 
150 Tropelías. Revista de Teoría de la Literatura y Literatura Comparada, 29 (2018) Idoli Castro

(2008): Colección de tapices. San Sebastián de los Reyes, CLUP. (2009): Desnudos y acuarelas. Madrid, Visor. (2009): Actos de habla. Barcelona, Plaza \& Janés.

Thelot, J. (1997): La poésie précaire. París, PUF.

VALENTE, J. A. (2005): Entrada en materia. Madrid, Cátedra. 